\title{
PERENCANAAN STRATEGI SISTEM INFORMASI DAN TEKNOLOGI INFORMASI KABUPATEN BULELENG DENGAN METODE WARD AND PEPPARD
}

\author{
I Putu Adhy Wicaksana Indra Saputra \\ Program Studi Ilmu Komputer, Program Pascasarjana Universitas Pendidikan Ganesha \\ Singaraja, Indonesia \\ e-mail: wicakjdm@gmail.com
}

\begin{abstract}
Abstrak
Penelitian ini bertujuan 1) untuk mendeskripsikan kondisi $\mathrm{SI} / \mathrm{TI}$ dan kondisi lingkungan bisnis yang sedang dijalankan pada Pemerintah Daerah Kabupaten Buleleng dan 2) untuk merumuskan rencana strategi SI/TI menggunakan framework Ward and Peppard untuk menunjang proses bisnis pada Pemerintah Daerah Kabupaten Buleleng. Metode pengumpulan data dalam penelitian ini menggunakan model perencanaan versi Ward and Peppard, yaitu Five Forces, PEST, Value Chain, Critical Success Factor, dan SWOT. Hasil analisis menunjukkan bahwa 1) Pada tahap analisis, dilakukan pemetaan mengenai kondisi SI/TI di area aplikasi, infrastruktur $\mathrm{TI}$, organisasi SI/TI, proses SI/TI dan 2) Metode Ward dan Peppard mampu menghasilkan strategi $\mathrm{SI} / \mathrm{TI}$ yang dalam bentuk renstra Pemerintah Kabupaten Buleleng. Saran-saran yang dapat diberikan adalah: 1) pemerintah Kabupaten Buleleng dapat menggunakan hasil pemetaan aplikasi, infrastruktur TI, organisasi SI/TI, dan proses SI/TI untuk meningkatkan implementasi SI/TI, 2) Bagi Dinas terkait diharapkan untuk mengajukan penambahan staf yang berlatar belakang SI/TI dan meningkatkan kuantitas dan kualitas pelatihan dan bimbingan teknis, dan 3) peneliti selanjutnya disarankan untuk meneliti perencanaan infrastruktur $\mathrm{SI} / \mathrm{TI}$ yang lebih mendalam mengenai proses bisnis Pemerintah Kabupaten Buleleng.
\end{abstract}

Kata kunci: perencanaan strategi, SI/TI, Ward and Peppard, Pemerintah Kabupaten Buleleng

\begin{abstract}
This study aims 1) to describe the condition of IS/IT and the condition of the business environment that is being carried out in the Regional Government of the Regency of Buleleng and 2) to formulate an IS/IT strategic plan using the Ward and Peppard framework to support business processes in the Regional Government of the Regency of Buleleng. Data collection methods in this study use Ward and Peppard version planning models, namely Five Forces, PEST, Value Chain, Critical Success Factor, and SWOT. The results of the analysis show that 1) During the analysis phase, mapping of the conditions of IS/IT in the application area, IT infrastructure, IS/IT organizations, IS/IT processes and 2) Ward and Peppard methods are able to produce IS/IT strategies in the form of strategic planning. Buleleng Regency Government. Suggestions that can be given are: 1) the government of Buleleng Regency can use the results of mapping applications, IT infrastructure, IS/IT organizations, and IS/IT processes to improve the implementation of IS/IT, 2) For the relevant Stakeholder it is expected to propose additional staff having an IS/IT background, increasing the competence of IS/IT human resources and increasing the quantity and quality of training and technical guidance, and 3) further researchers are advised to examine more in-depth IS/IT infrastructure planning regarding the Buleleng Regency Government business processes.
\end{abstract}

Keywords: strategy planning, IS/IT, Ward and Peppard, Buleleng Regency Government 


\section{PENDAHULUAN}

Perkembangan teknologi informasi dan komunikasi saat ini telah berkembang dengan pesat dan sangat mendukung untuk penyediaan berbagai informasi secara efisien dan efektif. Melihat perkembangan teknologi informasi yang dapat memberikan berbagai keuntungan membuat pemerintah mulai serius untuk mengimplemen-tasikannya. Hal ini bisa dilihat dengan diterbitkannya berbagai aturan yang menyangkut dengan penggunaan teknologi informasi dan komunikasi dalam lingkungan pemerintahan dan implementasi teknologi informasi dan komunikasi yang telah dilakukan oleh berbagai lembaga di pemerintahan baik di pusat maupun di daerah. Tidak sedikit organisasi ataupun lembaga pemerintahan melaksanakan pengembangan teknologi informasi hanya berdasarkan dari apa yang mereka percayai atau direkomendasikan oleh kolega atau vendor. Oleh karena itu, pengembangan Sistem Informasi dan Teknologi Informasi (SI/TI) memerlukan perencanaan yang sangat baik agar bisa mencegah kerugian yang lebih besar dari sisi finansial dan investasi.

Strategi SI/TI di lingkungan pemerintahan saat ini mengarah pada SI/TI sebagai penggerak bisnis utama di dalam aktivitas pengelolaan dan penyelenggaraan program pembangunan daerah. Salah satu upaya pemerintah Kabupaten Buleleng untuk meningkatkan efektivitas dan efisiensi fungsi pemerintahan berbasis elektronik atau e-government adalah dengan memanfaatkan SI dan TI secara optimal. Pemanfaatan teknologi secara baik dan benar diharapkan dapat memberikan manfaat dan nilai yang optimal bagi pemerintah daerah dan masyarakat yang dilayaninya.

Pemerintah Kabupaten Buleleng melangsungkan perencanaannya berdasarkan Rencana Pembangunan Jangka Menengah Daerah (RPJMD) tahun 2017-2022. Visi dan misi RPJMD Kabupaten Buleleng 2017-2022 adalah visi dan misi Kepala Daerah dan Wakil Kepala Daerah terpilih tahun 2017-2022 yang disampaikan kepada rakyat Buleleng pada Pemilihan Kepala Daerah tahun 2017. Visi
Kepala Daerah dan Wakil Kepala Daerah terpilih 2017-2022 yang menjadi visi RPJMD adalah: "Terwujudnya Masyarakat Buleleng yang Mandiri, Sejahtera, dan Berdaya Saing Berlandaskan Tri Hita Karana." Visi itu bermakna sebagai berikut.

Untuk mewujudkan visi tersebut maka tindakan yang akan dilakukan selama periode 2017-2022 adalah sebagai berikut:

1. Memantapkan Pembangunan Ekonomi untuk Mewujudkan Pertumbuhan Ekonomi yang Inklusif;

2. Pengembangan Ekonomi Kerakyatan yang Berbasis pada Produk Unggulan Daerah;

3. Meningkatkan Kualitas Sumber Daya Manusia yang Profesional, Berbudaya dan Berintegritas;

4. Memantapkan Partisipasi Pemangku Kepentingan dalam Pembangunan;

5. Meningkatkan Kuantitas dan Kualitas Infrastruktur Daerah untuk Pemenuhan Pelayanan Publik;

6. Mewujudkan Pembangunan Buleleng yang Berbudaya dan Berkelanjutan (Sustainable Development).

Strategi pembangunan daerah

Kabupaten Buleleng diharapkan dijadikan pedoman dalam mengimplementasikan program-program yang diprioritaskan oleh Kepala Daerah. Strategi pembangunan yang telah dirumuskan oleh Kepala Daerah diperjelas dengan arah kebijakan untuk mengarahkan rumusan strategi yang telah ditetapkan agar memiliki fokus dan target dalam pelaksanaannya lima tahun ke depan.

Penetapan isu strategis daerah untuk menjadi prioritas penanganan dalam perencanaan pembangunan 5 (lima) tahun ke depan mempertimbangkan kondisi dan dinamika yang terjadi pada lingkungan eksternal, kebijakan pembangunan jangka panjang daerah, dan rencana tata ruang wilayah.

Kondisi yang ada pada saat ini pada Pemerintah Kabupaten Buleleng dalam pemanfaatan $\mathrm{SI}$ dan $\mathrm{TI}$ adalah masingmasing Perangkat Daerah di Pemerintah Kabupaten Buleleng memiliki aplikasiaplikasi yang dikembangkan oleh pihak ketiga yang memiliki program dan struktur data yang bervariasi sehingga sulit untuk diintegrasikan. Selain itu, anggaran yang 
dikeluarkan untuk pemeliharaan server sangat tinggi jika diakumulasikan. Hal lain yang menjadi permasalahan adalah belum adanya kesamaan data sehingga hacker sangat mudah apabila ingin mengacaukan sistem informasi yang terdapat di Pemerintah Kabupaten Buleleng. Juga, belum optimalnya penerapan domain pada sistem informasi berbasis web. SDM untuk menangani permasalahan pada sistem informasi dan teknologi informasi masih kurang memadai sehingga masih tergantung pada pihak ketiga. Dan, tidak adanya evaluasi sistem informasi dan teknologi informasi dari perangkat daerah yang menangani hal tersebut.

Pemerintah Daerah Kabupaten Buleleng yang dipimpin oleh Kepala Daerah terpilih yang disebut dengan Bupati dan Wakil Bupati, dan Sekretaris Daerah (SEKDA) yang dibantu oleh beberapa Kepala Bagian, Pemerintah Daerah Kabupaten Buleleng memiliki 42 SKPD diantaranya 2 Sekretariat, 6 Badan, 1 Inspektur, 24 Dinas, dan 9 Kecamatan yang tersebar di Kabupaten Buleleng.

Perencanaan strategis sistem informasi didefinisikan sebagai proses mengidentifikasi suatu pemetaan aplikasi berbasis komputer yang akan membantu suatu organisasi dalam menjalankan perencanaan bisnisnya dan mewujudkan tujuan bisnisnya.

Teknologi informasi ( $\mathrm{TI})$ dilihat dari terdiri dari kata teknologi dan informasi. Kata teknologi bermakna penerapan berbagai peralatan atau sistem untuk menyelesaikan persoalan-persoalan yang dihadapi manusia dalam kehidupan sehari-hari. Kata teknologi berdekatan artinya dengan istilah tata cara. Informasi adalah data yang diolah menjadi bentuk yang lebih berguna bagi yang menerimanya (Jogiyanto, 2001).

Sistem informasi adalah "suatu sistem di dalam suatu organisasi yang mempertemukan kebutuhan pengolahan transaksi harian yang mendukung fungsi operasi organisasi yang bersifat manajerial dengan kegiatan strategi dari suatu organisasi untuk dapat menyediakan kepada pihak luar tertentu dengan laporanlaporan yang diperlukan" (Sutabri, 2012). Sistem informasi adalah: "Komponenkomponen yang saling berhubungan dan bekerja sama untuk mengumpulkan, memproses, menyimpan, dan menyebarkan informasi untuk mendukung pengambilan keputusan, koordinasi, pengendalian, dan untuk memberikan gambaran aktivitas di dalam perusahaan" (Susanto, 2013). Suatu sistem yang terdiri dari kumpulan komponen sistem, yaitu software, hardware, dan brainware yang memproses informasi menjadi sebuah output yang berguna untuk mencapai suatu tujuan tertentu dalam suatu organisasi.

Pendekatan metodologi versi Ward and Peppard ini dimulai dari kondisi investasi $\mathrm{SI} / \mathrm{TI}$ di masa lalu yang kurang bermanfaat bagi tujuan bisnis organisasi dan menangkap peluang bisnis, serta fenomena meningkatkan keunggulan kompetitif suatu organisasi karena mampu memanfaatkan $\mathrm{SI} / \mathrm{TI}$ dengan maksimal. Kurang bermanfaatnya investasi $\mathrm{SI} / \mathrm{TI}$ bagi organisasi disebabkan karena perencanaan strategis $\mathrm{SI} / \mathrm{TI}$ yang lebih fokus ke teknologi, bukan berdasarkan kebutuhan bisnis. Metodologi versi ini terdiri dari tahapan masukan dan tahapan keluaran (Ward et al., 2002).

Beberapa teknik/metode analisis yang digunakan dalam perencanaan strategis $\mathrm{SI} / \mathrm{TI}$ pada metodologi ini, mencakup analisis SWOT, analisis Five Forces Competitive, analisis Value Chain, metode Critical Succes Factors, metode Balanced Scorecard, dan McFarlan's Strategic Grid (Setiawan \& Yulianto, 2017).

\section{METODE}

Pada perencanaan strategi $\mathrm{SI} / \mathrm{TI}$ Pemerintah Daerah Kabupaten Buleleng, kerangka perencanaannya berdasarkan metodologi perencanaan menurut John Ward and Joe Peppard (Rifkhan \& Darwiyanto, 2011) (Gambar 1).

Tahap pertama adalah visi bisnis yang bertujuan untuk mendapatkan pemahaman tentang kondisi bisnis yang ada pada saat ini di dalam organisasi. Tahap Visi Bisnis terdiri dari dua proses, yaitu pertama memahami visi dan situasi bisnis, dan kedua hubungan bisnis dengan SI. Metode yang digunakan adalah wawancara dengan stakeholder, analisis Value Chain, dan SWOT. 


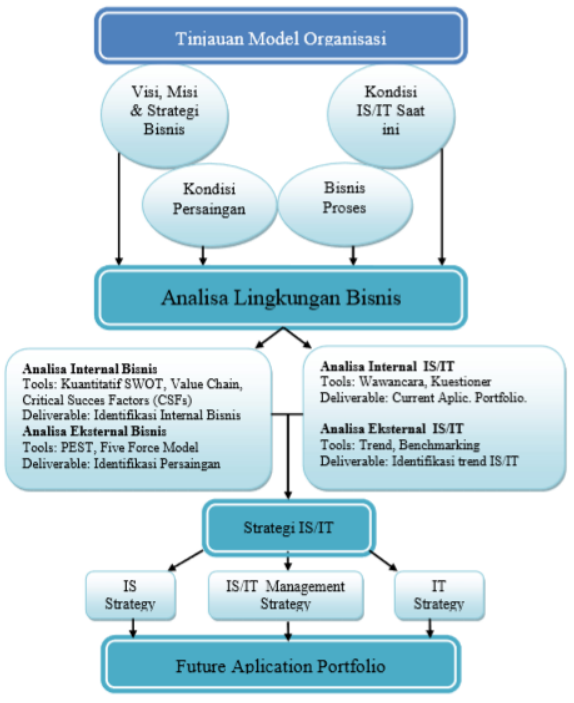

Gambar 1. Metodologi Berdasarkan Ward and Peppard

Tahap kedua adalah analisis yang terdiri dari tiga proses, yaitu pertama memahami kondisi $\mathrm{SI} / \mathrm{TI}$ saat ini, kedua menganalisis kondisi SI/TI saat ini, dan ketiga membangun rekomendasi solusi.

Tahap ketiga adalah arah pengembangan yang terdiri dari tiga proses, pertama membangun visi dan arah $\mathrm{SI} / \mathrm{TI}$, kedua mengembangkan rencana $\mathrm{SI} / \mathrm{TI}$, dan ketiga membangun proyek $\mathrm{SI} / \mathrm{TI}$. Proses pertama, membangun visi dan arah $\mathrm{SI} / \mathrm{TI}$, bertujuan untuk mendapatkan arahan level tinggi dari $\mathrm{SI} / \mathrm{TI}$ berupa visi $\mathrm{SI} / \mathrm{TI}$, misi $\mathrm{SI} / \mathrm{TI}$, tujuan $\mathrm{SI} / \mathrm{TI}$, dan strategi $\mathrm{SI} / \mathrm{TI}$. Metode yang digunakan untuk melakukan analisis data studi literatur dari keluaran tahapan Visi dan Analisis yang telah dipetakan sebelumnya.

Tahap terakhir atau tahap keempat yang rekomendasi, terdiri dari dua proses yaitu manajemen resiko proyek dan membangun roadmap. Keluaran yang diharapkan adalah ringkasan, anggaran, roadmap aplikasi bisnis, dan roadmap infrastruktur $\mathrm{TI}$, organisasi $\mathrm{SI} / \mathrm{TI}$, dan proses $\mathrm{SI} / \mathrm{Tl}$.

\section{HASIL DAN PEMBAHASAN}

Untuk mengetahui kondisi eksternal bisnis yang terjadi saat ini yang dapat berpengaruh langsung terhadap dalam perencanaan strategi $\mathrm{SI} / \mathrm{TI}$ Pemerintah Kabupaten Buleleng dilakukan dengan melakukan analisis PEST. Hasil dari analisis ini dijadikan sebagai acuan untuk menentukan strategi bisnis demi mencapai tujuan strategis. Hasil analisis PEST dalam perencanaan strategi $\mathrm{SI} / \mathrm{TI}$ Pemerintah Kabupaten Buleleng dapat dilihat pada Tabel 1 di bawah ini.

Tabel 1. Hasil Analis PEST pada Pemerintah Kabupaten Buleleng

\begin{tabular}{ll}
\hline Politik & - Dukungan sumberdaya manusia yang potensial dan berkualitas. \\
& - Adanya komitmen Pemda guna peningkatan kapasitas sumberdaya aparatur. \\
& - Motivasi dan keseriusan pegawai untuk menciptakan good governance. \\
& - Kebijakan dan regulasi pemerintah pusat yang mendukung perencanaan \\
& - Ketersediaan dokumen perencanaan sebagai referensi pengambilan \\
& kebijakan. \\
\hline Ekonomi & - Secara geografis merupakan daerah pariwisata. \\
& - Besarnya potensi investasi. \\
& - Berkembangnya hasil produksi wilayah. \\
& - Program pembangunan nasional dan daerah. \\
\hline Sosial dan & - Dukungan masyarakat adat (tanah). \\
Budaya & - Adanya interaksi wilayah lintas daerah. \\
& - Situasi dan kondisi daerah yang relatif kondusif. \\
& - Masih terjadi disparitas pembanguan antar daerah khususnya pedesaan. \\
\hline Teknologi & Perkembangan teknologi yang sangat cepat \\
\hline
\end{tabular}

Visi bisnis pemerintahan diidentifikasi dengan menggunakan value chain. Dengan melakukan penyesuaian konsep awal analisis Value Chain yang dikemukakan oleh Michael Porter untuk dimodifikasi agar sesuai dengan penggunaan pada organisasi pemerintahan. Dalam melakukan analisis, peneliti melakukan pengumpulan 
data dengan menggunakan studi literatur berdasarkan atas tugas pokok, fungsi, dan uraian tugas dari organisasi perangkat daerah yang terdapat di pemerintah Kabupaten Buleleng.
Berdasarkan aktivitias-aktivitas tersebut, value chain Kabupaten Buleleng dapat disajikan pada Gambar 2 berikut.

\begin{tabular}{|c|c|c|c|c|c|}
\hline \multirow{5}{*}{$\begin{array}{c}\text { Aktivitas } \\
\text { Pendukung }\end{array}$} & \multicolumn{5}{|c|}{$\begin{array}{l}\text { Kepegawaian: } \\
\text { lan pelaksanaan kebijakan pemerintahan di bidang } \\
\text { kepegawaian }\end{array}$} \\
\hline & \multicolumn{5}{|c|}{$\begin{array}{l}\text { Keuangan: } \\
\text { ola keuangan daerah }\end{array}$} \\
\hline & \multicolumn{5}{|c|}{$\begin{array}{l}\text { Koordinasi: } \\
\text { dalam menyusun kebijakan dan melakukan } \\
\text { aerah dan lembaga teknis daerah }\end{array}$} \\
\hline & \multicolumn{5}{|c|}{$\begin{array}{c}\text { Teknologi Informasi: } \\
\begin{array}{c}\text { Merencanakan dan melakukan koordinasi pemanfaatan serta penggunaan } \\
\text { teknologi komunikasi dan sistem informasi }\end{array}\end{array}$} \\
\hline & \multicolumn{5}{|c|}{$\begin{array}{l}\text { Pengadaan Perlengkapan: } \\
\text { Merealisasikan hasil perencanaan belanja modal, fisik, dan konsultasi }\end{array}$} \\
\hline $\begin{array}{l}\text { Aktivitas } \\
\text { Utama }\end{array}$ & $\begin{array}{c}\text { Perencanaan: } \\
\text { menjamin } \\
\text { agar } \\
\text { pembangunan } \\
\text { dapat berjalan } \\
\text { efektif dan } \\
\text { efisien }\end{array}$ & $\begin{array}{c}\text { Operasional: } \\
\text { memenuhi } \\
\text { sasaran } \\
\text { yang telah } \\
\text { ditetapkan } \\
\text { dalam } \\
\text { tujuan bisnis } \\
\text { masing- } \\
\text { masing } \\
\text { organisasi }\end{array}$ & $\begin{array}{c}\text { Pelayanan: } \\
\text { memberikan } \\
\text { pelayanan } \\
\text { yang baik } \\
\text { dan optimal } \\
\text { untuk setiap } \\
\text { urusan } \\
\text { administrasi } \\
\text { pemerintahan }\end{array}$ & $\begin{array}{l}\frac{\text { Monitoring }}{\text { dan }} \\
\text { Pelaporan: } \\
\text { memastikan } \\
\text { pelaksanaan } \\
\text { dan realisasi } \\
\text { program } \\
\text { kerja yang } \\
\quad \text { telah } \\
\text { ditetapkan }\end{array}$ & $\begin{array}{c}\text { Evaluasi, } \\
\text { Penelitian dan } \\
\text { Pengembangan: } \\
\text { Mengevaluasi } \\
\text { program kerja } \\
\text { yang telah } \\
\text { dilakukan oleh } \\
\text { SKPD }\end{array}$ \\
\hline
\end{tabular}

Gambar 2. Value Chain Pemerintah Kabupaten Buleleng

Analisis SWOT adalah analisis kondisi internal dan ekternal organisasi yang selanjutnya akan digunakan dasar untuk merancang strategi ke depan. Analisis internal meliputi penilaian terhadap faktor kekuatan (Strenght) dan kelemahan (Weakness), sementara analisis eksternal mencakup faktor peluang (Opportunity) dan Ancaman (Threath).

Posisi perencanaan strategi sistem informasi dan teknologi informasi Pemerintah Daerah Kabupaten Buleleng pada diagram kuadran SWOT pada Gambar 3 berikut.

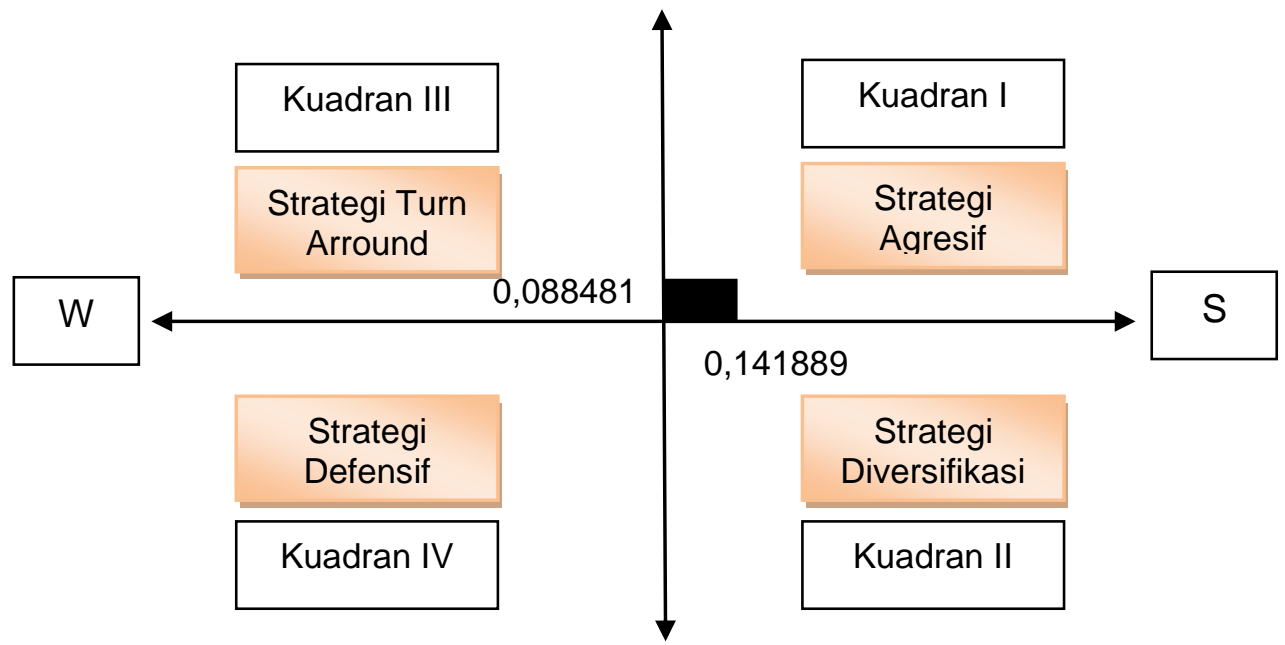

Gambar 3. Diagram Kuadran SWOT pada Perencanaan Strategi Sistem Informasi dan Teknologi Informasi Pemerintah Daerah Kabupaten Buleleng 
Berdasarkan hasil yang ditunjukkan pada diagram kuadran SWOT, maka dapat dijelaskan posisi perencanaan strategi sistem informasi dan teknologi informasi Pemerintah Daerah Kabupaten Buleleng berada pada kuadran I (positif, positif). Kuadran ini menggambarkan kondisi internal yang kuat dengan lingkungan yang mendukung untuk memanfaatkan peluang yang ada, sehingga arah, sasaran dan strategi yang sesuai untuk dijalankan bersifat agresif bagi pertumbuhan.

Berdasarkan hasil penjabaran strategi $\mathrm{SI} / \mathrm{TI}$ dan strategi bisnis, maka terbentuklah aplikasi portofolio dengan prioritas dan blueprint strategis $\mathrm{SI} / \mathrm{TI}$ yang berpedoman pada Strategic Grid McFarlan berdasarkan empat kuadran, yaitu strategic, key operational, high potential, dan support.

Tabel 2. Hasil Pemetaan Aplikasi Berdasarkan Matrik McFarlan Grid

Strategic
1. Sistem Informasi Eksekutif (SIE) (New)
2. Aplikasi Indikator Kemiskinan (Qlik
View) (Upgrade)
3. Aplikasi Informasi Pasar Kerja (IPK)
(Upgrade)
4. Sistem Informasi Pelayanan Tenaga
Kerja Asing Daerah (Upgrade)
5. Sistem Informasi Desa dan Kelurahan
(SIM Profil Desa) (Upgrade)
6. Online Monitoring Sistem
$\begin{aligned} & \text { Perbendaharaan Anggaran Negara } \\ & \text { (Omspan) (Upgrade) }\end{aligned}$
7. V-Planning (New)

High Potential

1. Sistem Informasi Aset Setda Kab. Buleleng (Upgrade)

2. RKPD Online / Sistem informasi perencanan pembangunan daerah (Sippeda) (New)

3. Sistem Informasi Perencanaan dan Penganggaran (SIPPA) Bidang Cipta Karya (Upgrade)

4. Aplikasi TNP2K (Tim Nasional Percepatan Penanganan Kemiskinan) (Upgrade)

5. Sistem Manajemen Informasi Objek Pajak (SISMIOP) (Upgrade)

6. Sistem Informasi Pendapatan Asli Daerah (SIMPAD) (Upgrade)

7. E-Inventory (Upgrade)

8. Pusat Layanan Kepegawaian (PILKBD) (Upgrade)

9. Aplikasi Data Pokok Pendidikan (Dapodik) (Upgrade)

10. Sistem Informasi Puskesmas (Upgrade)

11. Aplikasi Sistem Share Data Kependudukan (Upgrade)

12. Sistem Informasi Tim Evaluasi dan Pengawasan Realisasi Anggaran (TEPRA) (Upgrade)

13. Aplikasi sistem informasi database infrastruktur pekerjaan umum dan penataan ruang (Upgrade)

14. Sistem Informasi Desa (SID) (Upgrade)

15. Sistem Keuangan Desa (Siskeudes) (Upgrade)

16. Sistem Informasi Kesejahteraan Sosial New Generation (SIKS NG) (Upgrade)

17. Program Keluarga Harapan (PKH) (Upgrade)

18. Aplikasi perpustakaan slim (Upgrade)

Key Operational

1. Sistem Informasi Layanan Aspirasi dan Pengaduan Online Rakyat (Lapor SP4N) (Upgrade)

\section{Support}

1. Jaringan Data dan Informasi Hukum (JDIH) (Upgrade)

2. Aplikasi Percepatan Pembangunan 


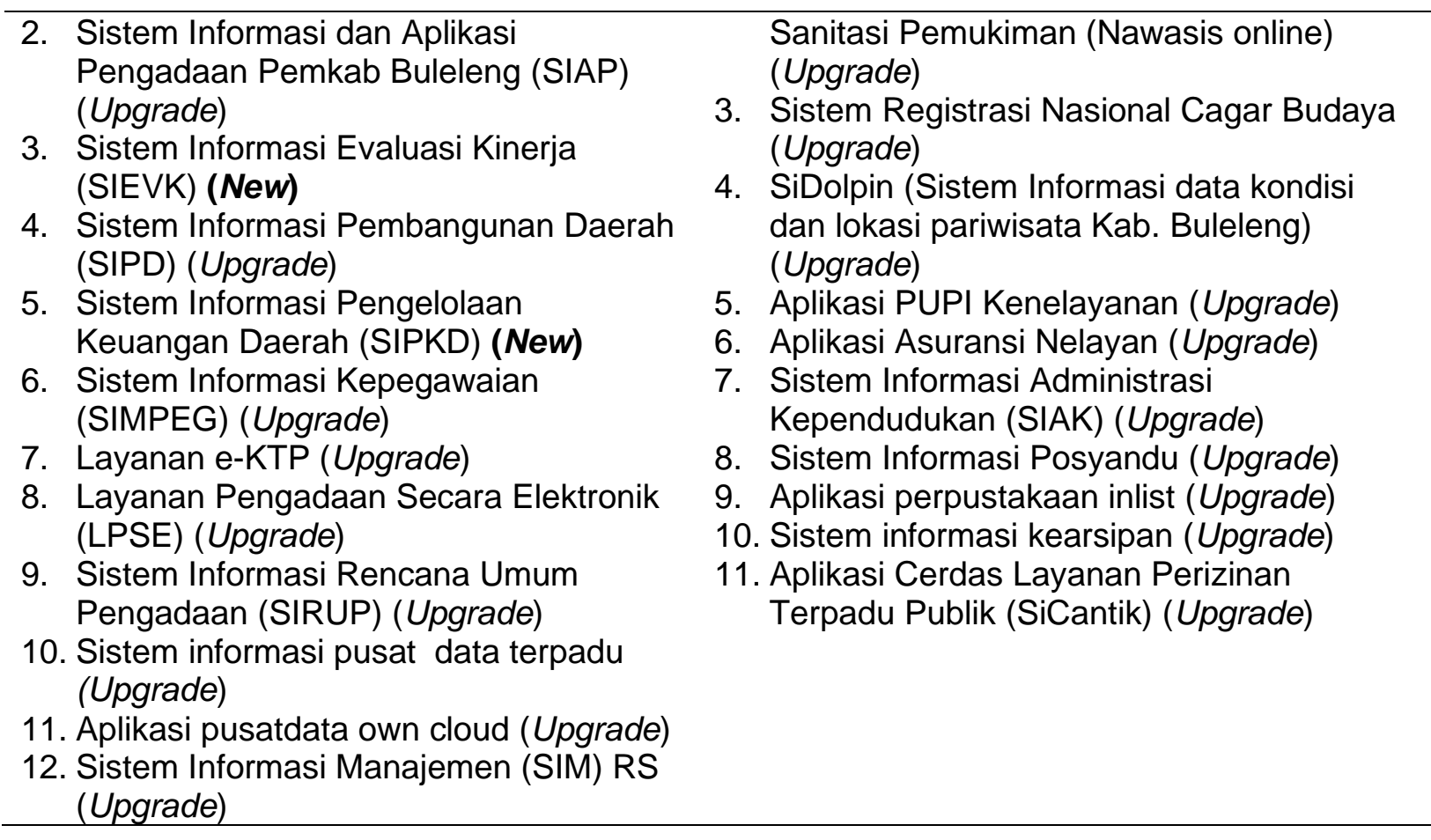

\section{A. Rencana Strategis Sistem Informasi dan Teknologi Informasi Pemerintah Daerah Kabupaten Buleleng \\ Rencana implementasi strategis $\mathrm{SI} / \mathrm{TI}$} ini merupakan rekomendasi yang disusun dalam betuk roadmap pengembangan $\mathrm{SI} / \mathrm{TI}$, namun penentuan prioritas pengerjaan nantinya akan dilakukan atas pertimbangan dan keputusan yang diambil oleh pihak manajemen Pemerintah Kabupaten Buleleng. Berdasarkan usulan strategi SI/TI dan Strategi Manajemen SI/TI yang telah dipetakan sebelumnya, selanjutnya perlu dibuatkan implementasi pengembangan strategi $\mathrm{SI} / \mathrm{TI}$ maupun Strategi Manajemen SI/TI dalam jangka waktu 5 tahun kedepan periode 2017 2022. Rencana strategis sistem informasi dan teknologi informasi Pemerintah Daerah Kabupaten Buleleng dapat dilihat pada Tabel 9 berikut.

Tabel 3. Rencana Strategis SI/TI Pemerintah Daerah Kabupaten Buleleng

\begin{tabular}{|c|c|c|c|c|}
\hline & Tujuan & Sasaran & Program/ Kegiatan & $\begin{array}{c}\text { Indikator Kinerja } \\
\text { Tujuan, Sasaran, } \\
\text { Program (outcome) } \\
\text { dan Kegiatan (output) }\end{array}$ \\
\hline \multirow[t]{4}{*}{1} & \multirow[t]{4}{*}{$\begin{array}{l}\text { Meningkatnya } \\
\text { kualitas e- } \\
\text { government } \\
\text { di Pemkab } \\
\text { Buleleng }\end{array}$} & $\begin{array}{l}\text { Mengingkatnya } \\
\text { kapasitas } \\
\text { cakupan } \\
\text { komunikasi } \\
\text { dan informasi }\end{array}$ & $\begin{array}{l}\text { Program Pengembangan } \\
\text { Komunikasi, Informasi dan } \\
\text { Media Masa }\end{array}$ & $\begin{array}{l}\text { Nilai SPBE (Sistem } \\
\text { Pemerintahan } \\
\text { Berbasis Elektronik) }\end{array}$ \\
\hline & & & $\begin{array}{l}\text { Pembinaan dan } \\
\text { pengembangan jaringan } \\
\text { informasi dan komunikasi }\end{array}$ & $\begin{array}{l}\text { Cakupan coverage } \\
\text { area komunikasi dan } \\
\text { informasi }\end{array}$ \\
\hline & & & $\begin{array}{l}\text { Pembinaan dan } \\
\text { Pengembangan sumber } \\
\text { daya komunikasi dan } \\
\text { informasi }\end{array}$ & $\begin{array}{l}\text { Jumlah titik jaringan } \\
\text { komputer yang dapat } \\
\text { berkomunikasi dengan } \\
\text { baik }\end{array}$ \\
\hline & & & $\begin{array}{l}\text { Penyediaan Layanan Akses } \\
\text { Internet }\end{array}$ & $\begin{array}{l}\text { Persentase } \\
\text { kehandalan server }\end{array}$ \\
\hline
\end{tabular}




\begin{tabular}{|c|c|c|}
\hline & \multirow[b]{2}{*}{$\begin{array}{l}\text { milik Pemkab Buleleng } \\
\text { Jumlah Instansi } \\
\text { Pemerintah yang dapat } \\
\text { terlayani akses internet } \\
\text { dengan baik } \\
\text { Jumlah titik layanan } \\
\text { free hotspot untuk } \\
\text { masyarakat } \\
\text { Jumlah masyarakat } \\
\text { yang menggunakan } \\
\text { media center }\end{array}$} \\
\hline & & \\
\hline \multirow[t]{5}{*}{ 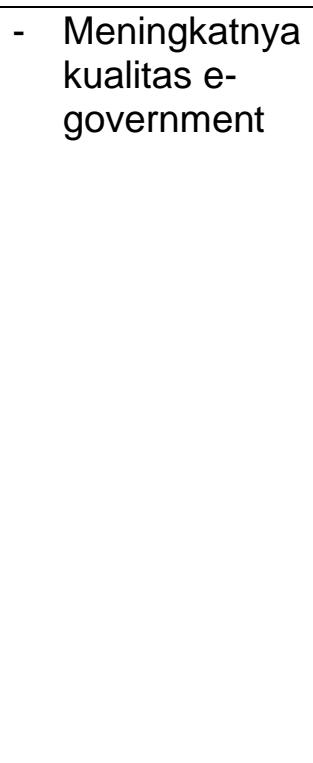 } & $\begin{array}{l}\text { Program Pengkajian dan } \\
\text { Penelitian Bidang } \\
\text { Komunikasi dan Informasi }\end{array}$ & $\begin{array}{l}\text { Persentase kajian } \\
\text { pengembangan TIK } \\
\text { yang diterapkan } \\
\text { dengan baik }\end{array}$ \\
\hline & $\begin{array}{l}\text { Pengkajian dan Penelitian } \\
\text { bidang informasi dan } \\
\text { komunikasi }\end{array}$ & $\begin{array}{l}\text { Jumlah dokumen } \\
\text { kajian pengembangan } \\
\text { dan inovasi TIK }\end{array}$ \\
\hline & $\begin{array}{l}\text { Pengumpulan dan } \\
\text { Pengolahan Data }\end{array}$ & $\begin{array}{l}\text { Jumlah jenis data yang } \\
\text { dikumpulkan dan } \\
\text { diolah }\end{array}$ \\
\hline & $\begin{array}{l}\text { Pengembangan dan } \\
\text { Pengelolaan Data Center }\end{array}$ & $\begin{array}{l}\text { Jumlah jenis data yang } \\
\text { disediakan pada data } \\
\text { center }\end{array}$ \\
\hline & $\begin{array}{l}\text { Pengkajian dan Integrasi } \\
\text { Sistem Informasi }\end{array}$ & $\begin{array}{l}\text { Jumlah sistem } \\
\text { infomasi yang } \\
\text { terintegrasi dengan } \\
\text { baik }\end{array}$ \\
\hline \multirow{3}{*}{$\begin{array}{l}\text { Meningkatnya } \\
\text { kapasitas } \\
\text { sumber daya } \\
\text { aparatur } \\
\text { pemerintah di } \\
\text { bidang } \\
\text { teknologi } \\
\text { informasi dan } \\
\text { komunikasi }\end{array}$} & $\begin{array}{l}\text { Program fasilitasi } \\
\text { peningkatan SDM bidang } \\
\text { komunikasi dan informasi }\end{array}$ & $\begin{array}{l}\text { Prosentase } \\
\text { peningkatan } \\
\text { pemahaman bidang } \\
\text { TIK }\end{array}$ \\
\hline & $\begin{array}{l}\text { Pelatihan SDM dalam } \\
\text { bidang komunikasi dan } \\
\text { informasi }\end{array}$ & $\begin{array}{l}\text { Jumlah SDM yang } \\
\text { meningkat } \\
\text { pengetahuannya } \\
\text { tentang pemanfaatan } \\
\text { sistem informasi } \\
\text { pemerintah }\end{array}$ \\
\hline & $\begin{array}{l}\text { Pengelolaan dan Fasilitas } \\
\text { Pengembangan SDM } \\
\text { bidang komunikasi dan } \\
\text { Informasi }\end{array}$ & $\begin{array}{l}\text { Jumlah pelatihan } \\
\text { komputer yang dapat } \\
\text { diselenggarakan pada } \\
\text { lab pelatihan komputer }\end{array}$ \\
\hline \multirow[t]{2}{*}{$\begin{array}{l}\text { - } \text { Meningkatnya } \\
\text { kualitas } \\
\text { layanan } \\
\text { pemerintah } \\
\text { berbasis } \\
\text { elektronik }\end{array}$} & $\begin{array}{l}\text { Program Pengelolaan } \\
\text { Layanan e-Government }\end{array}$ & $\begin{array}{l}\text { Persentase SKPD } \\
\text { Pemerintah Kab. } \\
\text { Buleleng yang } \\
\text { menggunakan } \\
\text { naplikasi/ sistem } \\
\text { informasi }\end{array}$ \\
\hline & $\begin{array}{l}\text { Pengelolaan Layanan } \\
\text { Secara Elektronik }\end{array}$ & $\begin{array}{l}\text { Jumlah layanan } \\
\text { pemerintah secara } \\
\text { elektronik yang dapat } \\
\text { berjalan dengan baik }\end{array}$ \\
\hline
\end{tabular}




\begin{tabular}{|c|c|c|c|}
\hline & & $\begin{array}{l}\text { Pembuatan, } \\
\text { Pengembangan dan } \\
\text { Pemeliharaan Aplikasi } \\
\text { Pemerintahan dan } \\
\text { Pelayanan Publik }\end{array}$ & $\begin{array}{l}\text { Jumlah aplikasi } \\
\text { pemerintah yang } \\
\text { diimplementasi- kan }\end{array}$ \\
\hline & & $\begin{array}{l}\text { Pengelolaan Nama Domain } \\
\text { dan Sub Domain }\end{array}$ & $\begin{array}{l}\text { Jumlah nama domain } \\
\text { dan subdomain yang di } \\
\text { lingkup Pemkab } \\
\text { Buleleng yang } \\
\text { dimonitor } \\
\text { Jumlah nama domain } \\
\text { dan sub domain yang } \\
\text { berhasil didaftarkan }\end{array}$ \\
\hline & & $\begin{array}{l}\text { Pembinaan dan } \\
\text { Pengembangan Situs resmi } \\
\text { Pemerintah Daerah }\end{array}$ & $\begin{array}{l}\text { Jumlah sub domain } \\
\text { pada situs resmi } \\
\text { Pemkab Buleleng yang } \\
\text { terkelola dengan baik }\end{array}$ \\
\hline & & $\begin{array}{l}\text { Pengkajian dan } \\
\text { Pengembangan } \\
\text { Implementasi e- } \\
\text { Government }\end{array}$ & $\begin{array}{l}\text { Jumlah regulasi terkait } \\
\text { implementasi e- } \\
\text { government yang } \\
\text { ditetapkan dengan } \\
\text { peraturan kepala } \\
\text { daerah } \\
\text { Jumlah dokumen } \\
\text { kerjasama dalam } \\
\text { bidang e-government } \\
\text { yang diterbitkan dan } \\
\text { ditindaklanjuti }\end{array}$ \\
\hline & & $\begin{array}{l}\text { Peningkatan kapasitas } \\
\text { aparatur dan Sertifikasi } \\
\text { teknis bidang TIK }\end{array}$ & $\begin{array}{l}\text { Jumlah tenaga teknis } \\
\text { yang meningkat } \\
\text { pengetahuannya } \\
\text { dibidang TIK }\end{array}$ \\
\hline $\begin{array}{l}2 \text { Meningkatnya } \\
\text { kualitas } \\
\text { pengamanan }\end{array}$ & & & $\begin{array}{l}\text { Persentase keamanan } \\
\text { komunikasi dan } \\
\text { informasi }\end{array}$ \\
\hline & $\begin{array}{l}\text { - } \text { Meningkatnya } \\
\text { keamanan } \\
\text { komunikasi } \\
\text { dan informasi } \\
\text { pada kegiatan }\end{array}$ & $\begin{array}{l}\text { Program Optimalisasi } \\
\text { Pemanfaatan Teknologi } \\
\text { Informasi }\end{array}$ & $\begin{array}{l}\text { Persentase Perangkat } \\
\text { daerah yang telah } \\
\text { menggunakan sandi } \\
\text { dalam komunikasi } \\
\text { Perangkat Daerah }\end{array}$ \\
\hline & & $\begin{array}{l}\text { Pengelolaan Sumber Daya } \\
\text { Persandian }\end{array}$ & $\begin{array}{l}\text { Jumlah dokumen } \\
\text { kebijakan terkait } \\
\text { pengamanan data dan } \\
\text { informasi lingkup } \\
\text { Pemkab Buleleng yang } \\
\text { disusun dan ditetapkan } \\
\text { dengan keputusan } \\
\text { kepala daerah }\end{array}$ \\
\hline
\end{tabular}


Pembinaan dan

Pengembangan SDM

bidang persandian
Jumlah aparatur yang

meningkat

kemampuannya

dibidang persandian

Jumlah instansi

pemerintah yang

bebas dari gangguan

keamanan informasi

Pengelolaan Pengamanan
Informasi dan Komunikasi

Sandi

Jumlah obyek

pengamanan

persandian yang

berhasil diamankan

dari gangguan

keamanan informasi

dan komunikasi

Pengawasan dan Evaluasi Jumlah dokumen

Penyelenggaraan

Persandian laporan pelaksanaan

persandian yang

disusun dan

disampaikan tepat

waktu

\section{PENUTUP}

Berdasarkan temuan-temuan penelitian maka disajikan beberapa kesimpulan sebagai berikut.

1. Pada tahap analisis, proses yang dilakukan adalah menganalisa kondisi $\mathrm{SI} / \mathrm{TI}$. Pada tahap ini, dilakukan pemetaan mengenai kondisi $\mathrm{SI} / \mathrm{TI}$ di area aplikasi, infrastruktur TI, organisasi $\mathrm{SI} / \mathrm{TI}$, proses SI/TI. Pada tahap analisis ini ditemukan beberapa kelemahan. Adapun kelemahan-kelemahan tersebut, yaitu:

a. Ketersediaan sumberdaya manusia.

b. Tidak adanya arahan yang jelas dari pusat ataupun propinsi tentang kelembagaan e-Government.

c. Tidak ada standar spesifikasi pada lingkungan komputer

d. Pemeliharaan dan perawatan tidak dilakukan dengan baik

e. Data tidak terintegrasi dengan aplikasi lain

f. Banyak modul aplikasi yang belum terpakai

2. Metode Ward dan Peppard mampu memberikan usulan-usulan $\mathrm{SI} / \mathrm{TI}$ yang strategis yang menghasilkan portfolio SI dan kondisi SI/TI yang secara keseluruhan mampu mendukung

\section{pencapaian sasaran strategis}

Pemerintah Kabupaten Buleleng.

Metode Ward dan Peppard mampu menghasilkan strategi $\mathrm{SI} / \mathrm{TI}$ yang dalam bentuk renstra Pemerintah Kabupaten Buleleng sehingga akuntabilitas pengelolaan SI/TI meningkat.

Berdasarkan kesimpulan yang telah diuraikan di atas maka dapat diberikan saran-saran sebagai berikut.

1. Bagi Pemerintah Kabupaten Buleleng Pemerintah Kabupaten Buleleng dapat menggunakan hasil pemetaan aplikasi, infrastruktur $\mathrm{TI}$, organisasi $\mathrm{SI} / \mathrm{TI}$, dan proses $\mathrm{SI} / \mathrm{TI}$ untuk meningkatkan implementasi $\mathrm{SI} / \mathrm{TI}$ dalam membantu tujuan bisnis Pemerintah Kabupaten Buleleng.

2. Bagi Dinas Terkait

Bagi Dinas terkait diharapkan untuk mengajukan penambahan staf yang berlatar belakang $\mathrm{SI} / \mathrm{TI}$, meningkatkan kompetensi SDM SI/TI, menerbitkan regulasi dan standar yang terkini mengenai spesifikasi minimal yang menjadi acuan bagi semua SKPD, menerapkan prosedur pemeliharaan rutin dan melakukan pengecekan berkala pada semua infrastruktur, dan meningkatkan kuantitas dan kualitas 
pelatihan dan bimbingan teknis.

3. Bagi Peneliti Selanjutnya

Peneliti selanjutnya disarankan untuk meneliti perencanaan infrastruktur SI/TI yang lebih mendalam mengenai proses bisnis Pemerintah Kabupaten Buleleng.

\section{DAFTAR PUSTAKA}

Jogiyanto, H. M. (2001). Analisis dan Desain Sistem Informasi Edisi Kedua. Andi Offset. Yogyakarta.

Sutabri, T. (2012). Analisis sistem informasi. Penerbit Andi.

Susanto, A. (2013). Sistem Informasi Akuntansi. Bandung: Lingga Jaya.

Ward, J., Griffiths, P. M., \& Whitmore, P. (2002). Strategic planning for information systems (Vol. 3). Chichester: Wiley.

Setiawan, A., \& Yulianto, E. (2017). Information System Strategic Planning Using IT Balanced Scorecard In Ward \& Peppard Framework Model. International Journal of Engineering and Technology (IJET), 9(3), 1864-1872.

Rifkhan, M., \& Darwiyanto, E. (2011). Perencanaan Strategi Sistem Informasi/Teknologi Informasi Menggunakan Kerangka The Open Group Architecture Framewrok (TOGAF) Architecture Development Method (ADM), Studi Kasus: Sekretariat Badan Perencanaan dan Pembangunan Daerah Provinsi Sulawesi Tengah. Telkom University. Bandung. 